\title{
DESIGN DE LIVROS EM LIBRAS PARA O ENSINO DE PORTUGUÊS A CRIANÇAS SURDAS
}

\section{DESIGN OF BOOKS WITH SIGN LANGUAGE AS AID FOR DEAF CHILDREN TO LEARN PORTUGUESE}

\author{
Silvina Ruth Crenzel $^{1}$, D.Sc. \\ Ana Lucia Alexandre Zandomeneghi ${ }^{2}$, D.Sc. \\ (1) UFMA \\ e-mail: silvinaphd@gmail.com \\ (2) UFMA \\ e-mail: ana.zandomeneghi@ufma.br
}

Palavras-chave: Animação, LIBRAS, Livro digital

Neste artigo apresentamos resultados obtidos ao longo de uma extensa pesquisa junto a crianças surdas utilizando livros digitais com ilustrações coloridas, recursos animados, texto verbal e vídeos com tradução a libras como suporte para o ensino de português a esse público. As descobertas resultantes do trabalho realizado poderão subsidiar a criação de narrativas lúdicas, materiais didáticos e paradidáticos para crianças e jovens nos mais diversos estágios de desenvolvimento linguístico auxiliando-as a ampliarem seus repertórios de conceitos sígnicos verbais e não verbais e, assim, colaborar em sua inserção na sociedade como cidadãos plenos.

\section{Key-words: Animation, Sign language, Digital, E-book}

This paper brings the outcome of a long length research conducted with deaf children using digital narratives with colorful illustrations, animations, verbal text and videos translating the linguistic content to sign language. The goal was to find a way to aid these children learn Portuguese, which is their second language, being LIBRAS (Brazilian Sign Language), their main means of communication. The results may subsidize the creation of new literary narratives and educational materials that can help these children broaden their signs repertoire, both verbal and non verbal,, and, thus, enhance their chances of inclusion in society. 
 \\ ERGODESIGN USIHC CINAHPA}

\section{Introdução}

As crianças que hoje estão em idade escolar nasceram em meio a uma revolução tecnológica digital e convivem naturalmente com os recursos a ela vinculados, mesmo entre camadas menos favorecidas socioeconômico e culturalmente da população. Em muitas escolas, monitores de vídeo, lousas digitais e computadores conectados à Internet convivem, já há alguns anos, com lápis, cadernos e livros. Mais recentemente, o uso de tablets - com função de $e$-readers - e smartphones também vêm sendo incorporados como suportes para material didático em instituições de ensino de todos os segmentos.

Aplicativos desenvolvidos para facilitar a aprendizagem de diversas disciplinas surgem constantemente nas lojas virtuais de todos os sistemas operacionais para dispositivos móveis e computadores, abrangendo temas tão diversos como matemática (GeoGebra ${ }^{1} \mathrm{e}$ Brilliant ${ }^{2}$, por exemplo) e química (Learn Organic Chemistry ${ }^{3}$ ). Esses incorporam recursos e funções multimídia de forma eficiente e explorando de maneira inteligente as possibilidades dos meios e suportes digitais.

Porém, na esfera da literatura, ainda são raras as obras com versões de narrativa digital que incorporem recursos multimídia, para qualquer público. Para crianças pequenas existem algumas alternativas, mas ainda são pobres, no sentido de não explorarem adequadamente $o$ que o universo digital tem a proporcionar, a exemplo da ICDL, International Children's Digital Library ${ }^{4}$ e o portal Biblon que somente reproduzem imagens estáticas com texto e ilustrações idênticos aos das versões impresas, ou Alice no País das Maravilhas para iPad ${ }^{5}$, que conta com alguns recursos de animação e botões interativos.

\footnotetext{
${ }^{1}$ Disponível em: https://www.geogebra.org/ Acesso em 20/3/2016

2 Disponível em: https://brilliant.org/ Acesso em 20/3/2016

${ }^{3}$ Disponivel na Apple Store e Google Play
}

$16^{\circ}$ Ergodesign - Congresso Internacional de Ergonomia e Usabilidade de Interfaces Humano Tecnológica: Produto, Informações Ambientes Construídos e Transporte

$16^{\circ}$ USIHC - Congresso Internacional de Ergonomia e Usabilidade de Interfaces Humano Computador

CINAHPA | 2017 - Congresso Internacional de Ambientes Hipermídia para Aprendizagem.

Em pesquisa com crianças de 8 a 11 anos (Crenzel, 2009), comprovou-se que recursos multimídia incorporados a histórias literárias em suportes digitais ampliam a capacidade de apreensão dos conteúdos de narrativas e aquisição de vocabulário por jovens leitores. Para o público infantil, que fantasia com facilidade e se imbui de cenários e situações fictícias para brincar, textos acompanhados por ilustrações animadas e interatividade, possibilitaram apreensão de conteúdos mais significativa pela leitura das mesmas estórias em suportes convencionais impressos (Crenzel, 2009). Ao longo de uma extensa pesquisa de doutorado e duas pesquisas de iniciação científica que a subsidiaram evidenciou-se que fato imagens pictóricas animadas colaboram no processo de apreensão de conteúdos narrativos pelo fácil reconhecimento dos objetos que as compõem em contraposição ao uso exclusivo de recursos linguísticos acompanhados de imagens pictóricas estáticas.

As pesquisas acima mencionadas foram conduzidas com sujeitos sem limitações físicas, ou seja, crianças com capacidades cognitivas na média esperada para a faixa etária em estudo, que enxergam e ouvem normalmente. Isso quer dizer que essas crianças têm um repertório linguístico e conceitual padrão para sua idade cronológica e desenvolvimento intelectual.

Para o surdo, no Brasil, o português é uma segunda língua, sendo a LIBRAS - linguagem brasileira de sinais - a primeira. Diferentemente de língua estrangeira, segunda língua é uma com a qual o sujeito convive em seu país.

Cabe ressaltar que são poucas as crianças surdas ou com sérias dificuldades auditivas com repertório conceitual, cultural e simbólico e que conseguem ler e escrever em português ${ }^{5}$ como seus pares sem

\footnotetext{
4 Disponível em:http://en.childrenslibrary.org/ acesso em 30/4/2015 ${ }^{5}$ Disponível na App Store desde 2011

${ }^{5}$ Considerando sempre, neste estudo, a criança brasileira.
} 



CINAHPA

qualquer limitação física. Essas poucas, em geral, sabem fazer leitura labial e enfrentam menos entraves de comunicação escrita com a sociedade ouvinte. A maioria, entretanto, por nunca ter conseguido ouvir, têm muita dificuldade para expressar-se (no Brasil) em português. Esses indivíduos, muitas vezes, enfrentam sérias dificuldades para compreender textos verbais escritos, pois a forma como estruturam a linguagem é muito diferente à das pessoas que nunca tiveram limitações auditivas. Surdos aqui dependem da linguagem brasileira de sinais - LIBRAS - para comunicar-se entre si e com os que não são surdos, normalmente com a ajuda de intérpretes bilíngues.

Em geral, o surdo aprende português na escola e a obrigatoriedade é que ele aprenda modalidade escrita - a ler e a escrever. Entretanto, o ensino dessa modalidade escrita tem passado por muitos problemas por não haver métodos que orientem sobre como ensinar aos surdos: "não há um manual que diga como ensinar português aos surdos. Isso ainda está sendo construído [...] O surdo tem potencial para aprender a língua portuguesa. $\mathrm{O}$ problema está no sistema, não nos surdos" (Alves, 2014).

Existem diversos produtos à disposição de pessoas com necessidades especiais, como pode ser visto no guia disponível no site surdo.com.br ${ }^{6}$, mas há uma importante lacuna no que tange a produtos para facilitar a compreensão dos significados do que está expresso em linguagem verbal escrita.

Pesquisadores e educadores têm tentado diversos métodos para auxiliar surdos na aquisição da língua portuguesa (Pereira, 2002) e espera-se que em um futuro próximo se possa encontrar o melhor caminho para ensinar pessoas surdas a dominar a língua da qual dependem para comunicar-se eficientemente com pessoas falantes e ouvintes, uma vez que são raros os casos de não surdos que entendem LIBRAS (Alves, 2014).

\footnotetext{
6

http://www.surdo.com.br/download/Abteca_Guia_Produt os_para_pessoas_com_deficien cia.pdf
}

$16^{\circ}$ Ergodesign - Congresso Internacional de Ergonomia e Usabilidade de Interfaces Humano Tecnológica: Produto, Informações Ambientes Construídos e Transporte

$16^{\circ}$ USIHC - Congresso Internacional de Ergonomia e Usabilidade de Interfaces Humano Computador

CINAHPA | 2017 - Congresso Internacional de Ambientes Hipermídia para Aprendizagem.

Sendo o aprendizado do português por surdos algo que deve começar na infância, um ponto bem importante a discutir é que um trabalho com contos infantis deve ser feito com esse público. O contato com essas narrativas contribui com seu letramento (Alves, 2014), que vai muito além da aprendizagem da mecânica da alfabetização: trata-se da "alfabetização funcional".

"O contato com literatura infantil amplia a visão de mundo, o conhecimento de mundo da criança surda" (Alves, 2014). Além disso, ela partilhará do conhecimento de histórias que crianças ouvintes têm. Isso pouco acontece atualmente. Muitas crianças surdas não têm acesso aos contos que a maioria conhece, muitas vezes desde bem pequenas, pela leitura de seus pais e cuidadores na hora de dormir, por exemplo. Ao tomar conhecimento das histórias que as crianças ouvintes e falantes têm, a criança surda passará a compartilhar desse conhecimento.

A importância do trabalho com a literatura infantil com crianças surdas também reside no fato de que as prepara para que, com acesso a textos diferenciados a partir do momento que existe a intertextualidade, elas consigam compreender informações transmitidas através, por exemplo, de uma citação de uma personagem de uma história infantil. Quando se faz referência a uma personagem há intenção de passar uma significação e só a compreende a pessoa que conhece a história e universo na qual a personagem está inserida. "Se ela conhece consegue apreender esse conhecimento, trazê-lo para o texto e dialogar com o texto, que é o que o leitor ouvinte faz. A leitura é indicada para qualquer criança, isso inclui a criança surda" (Alves, 2014).

Conforme um artigo publicado em 2005, pela Organização das Nações Unidas para a Educação, a Ciência e a Cultura (UNESCO) em preparação para o segundo encontro do World Summit on the Information Society, "Negar acesso à informação na 


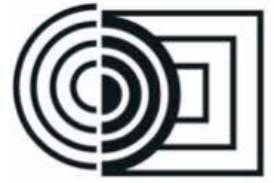

língua natal de alguém equivale a negar um direito humano" [...], "Em termos de pedagogia, como as crianças aprendem melhor? Em sua língua materna."

Entretanto, como fica a situação dos surdos, cuja "língua materna" depende de sinais e não da expressão oral?

A proposta desta pesquisa foi a de levar uma narrativa literária animada ao universo de crianças surdas, que dependem da linguagem brasileira de sinais - Libras - para comunicar-se e que, por isso, têm uma compreensão do mundo e das palavras muito diferente ao das pessoas que não têm limitações de fala e audição. Coletamos indícios de que o reforço visual das animações em histórias em paralelo com narração em LIBRAS e texto verbal impresso aumenta a apreensão do conteúdo, e, particularmente e em primeiro lugar, a fruição dessas histórias por esse público.

Crianças que são bem alfabetizadas têm maiores chances de tornar-se adultos leitores. Pessoas que leem bem com frequência são pessoas mais bem informadas. A plena compreensão da linguagem verbal escrita é uma importante porta para o exercício da plena cidadania (Ferreiro, 2001). Com este trabalho conseguimos apresentar uma forma de abrir essa porta um pouco mais para crianças surdas virem a tornar-se cidadãos plenos, logo, integrados ao universo dos ouvintes com que convivem.

\section{Referencial teórico}

\subsection{Dificuldades da criança surda para alfabetização em português}

A alfabetização, ou seja, a aquisição do domínio pleno da escrita e da leitura, requer um longo período de aprendizado que está longe de se esgotar nos primeiros anos de escolaridade.

Inicialmente, a relação entre as marcas gráficas e a linguagem é uma relação mágica, que põe em jogo uma tríade: um intérprete, uma criança e um

\footnotetext{
7 Tradução livre. According to a paper published in 2005 by
} the United Nations Educational Scientific and $16^{\circ}$ Ergodesign - Congresso Internacional de Ergonomia e Usabilidade de Interfaces Humano Tecnológica: Produto, Informações Ambientes Construídos e Transporte

$16^{\circ}$ USIHC - Congresso Internacional de Ergonomia e Usabilidade de Interfaces Humano Computador

CINAHPA | 2017 - Congresso Internacional de Ambientes Hipermídia para Aprendizagem.

conjunto de marcas. O Intérprete (que, em sentido estrito, deveríamos chamar de "interpretante"(...), ao efetuar esse ato aparentemente banal que chamamos de "ato de leitura", informa à criança que essas marcas têm poderes especiais: só de olhá-las se produz a linguagem (FERREIRO, 2002, p. 27). Há crianças que ingressam na língua escrita por meio dessa relação mágica e se tornarão leitoras. Outras têm barreiras que bloqueiam essa magia e entram na escrita pelas "habilidades básicas”. O destino destas é incerto (Op.cit).

O que dizer, então, das dificuldades que crianças surdas enfrentam para alcançar um nível de alfabetização que, pelo menos, as aproxime do que Emília Ferreiro (2002) classifica de "habilidades básicas", sendo que para a autora, o domínio dessas "habilidades básicas" ainda lhes reserva um "destino incerto"? (Op. Cit).

Com base em meta análises de pesquisas com crianças sem problemas de audição nos Estados Unidos, o National Early Literacy Panel (NELP, 2008) concluiu que uma importante questão na apreensão da leitura da linguagem verbal escrita requer que todas as crianças em idade pré-escolar dominem duas habilidades fundamentais: a habilidade baseada em reconhecimento de códigos para conseguir decodificar palavras, ou seja, reconhecimento de sons (reconhecimento fonológico), conhecimento do alfabeto e conceitos da representação impressa dos sons, e a habilidade de entender os significados e ideias que a decodificação de palavras se propõe a transmitir, ou seja, conhecimento de vocabulário e compreensão da linguagem verbal. (Lederberg et al., 2014).

Os autores desse estudo reconhecem que muito se progrediu recentemente no que tange a melhorar as técnicas de ensino para que crianças ouvintes e falantes possam dominar essas habilidades, ainda que pouco se saiba ainda sobre como facilitar o desenvolvimento nessa esfera das crianças com deficiências auditivas, muito embora esteja bem documentado o fato de a maioria dessas crianças ingressarem na escola em grande desvantagem

Cultural Organization (UNESCO) in preparation for the second meeting on the World Summit on the Information
Realização:
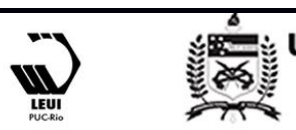


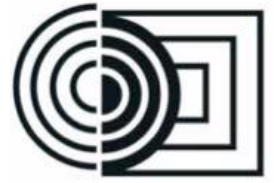

ERGODESIGN USIHC CINAHPA

quanto ao domínio dos recursos linguísticos de comunicação e expressão que seus pares ouvintes (Lederberg, Schick, \& Spencer, 2013) ${ }^{8}$.

\subsection{Narrativas e ilustrações para crianças}

Uma narrativa é uma história que pode ser contada de várias formas, envolvendo personagens, o que dizem e o que fazem. Em literatura, romances e épicos são narrativas explícitas contadas por um narrador; nas dramatizações, a narrativa não é contada, mas desenvolve-se pela apresentação em cena das ações e falas das personagens (Abrahams, 1999).

O que aqui definimos como livro infantil ilustrado é, portanto, o texto que conta uma história com palavras e ilustrações. Cecília Meireles (1979) diz que livro infantil é aquele escrito para crianças, e tem como objetivo básico contar uma história (Lins, 2002).

No caso das narrativas para crianças a revolução tecnológica trouxe novos suportes, como CDROMs com atividades interativas de todos os tipos, aplicativos para computadores pela Internet muitos surgidos nas últimas duas décadas do século XX -, e os e-readers e smartphones com (que, hoje, são o auge da sofisticação para transmissão de conteúdos interativos com base em incontáveis aplicativos.

\subsection{Cuidados para com o Livro infantil}

O livro infantil é "um produto no qual convivem interpretação de texto, projeto gráfico, as mais variadas técnicas de ilustração e todos os recursos das artes gráficas disponíveis" (LINS, 2002, p. 12). A elaboração deste tipo de objetos requer atenção cuidadosa quanto à ilustração, no sentido de atribuir-lhe uma significação para além de meramente estética. A ilustração deve servir como complemento do texto, além de cumprir uma série de outras funções: $16^{\circ}$ Ergodesign - Congresso Internacional de Ergonomia e Usabilidade de Interfaces Humano Tecnológica: Produto, Informações Ambientes Construídos e Transporte

$16^{\circ}$ USIHC - Congresso Internacional de Ergonomia e Usabilidade de Interfaces Humano Computador

CINAHPA | 2017 - Congresso Internacional de Ambientes Hipermídia para Aprendizagem.

Muito mais do que apenas ornar ou elucidar o texto, a ilustração pode, assim, representar, descrever, narrar, simbolizar, expressar, brincar, persuadir, normatizar, pontuar, além de enfatizar sua própria configuração, chamar atenção para o seu suporte ou para a linguagem visual (Camargo, 1995) ${ }^{9}$.

O leitor, frequentemente, deduz o sentido do texto sem a mediação de todas as palavras, com base em algumas pistas visuais utilizando seu conhecimento prévio do mundo. Na presença de imagens pictóricas, extrai destas a apreensão de um significado, de modo imediato -Algum significado, aquele que esses dados combinados puderem construir por meio de inferências (Fulgêncio \& Liberato, 2002).

As ilustrações, entendidas como imagens pictóricas que acompanham textos, não têm função isolada. Texto e imagem devem estar correlacionadas e devem fazer sentido para o leitor. Referimo-nos a essa relação como coerência intersemiótica, ampliando o conceito de coerência textual.

[...] a convergência ou não-contradição entre os significados denotativos e conotativos da ilustração e do texto. Como essa convergência só ocorre nos casos ideais, pode-se falar em três graus de coerência: a convergência, o desvio e a contradição. Avaliar, portanto, a coerência entre uma determinada ilustração e um determinado texto significa avaliar em que medida a ilustração converge para os significados do texto, deles se desvia ou os contradiz (Camargo, 1995).

Livros infantis ilustrados comunicam tradicionalmente - por meio das imagens pictóricas e palavras escritas. Para que as crianças consigam compreendê-los, além de se cuidar da já discutida necessidade de haver coerência intersemiótica é necessário passar a mensagem desejada com clareza. 
$16^{\circ}$ Ergodesign - Congresso Internacional de Ergonomia e Usabilidade de Interfaces Humano Tecnológica: Produto, Informações Ambientes Construídos e Transporte

$16^{\circ}$ USIHC - Congresso Internacional de Ergonomia e Usabilidade de Interfaces Humano Computador

CINAHPA | 2017 - Congresso Internacional de Ambientes Hipermídia para Aprendizagem.

\subsection{Suportes digitais para narrativas $e$ desenvolvimento infantil}

Livros digitais infantis são uma forma de narrativa que podem integrar, com efeitos multimídia, texto escrito, leitura oral, música, efeitos sonoros e animações. As imagens ou textos podem ter "hot spots" para serem ativados pelos leitores/usuários (Madej, 2003; De jong \& Bus, 2000; Korat \& Shamir, 2006), que, a partir deste ponto, serão chamados interatores.

A pesar das críticas recebidas desde seu advento como equipamento de uso doméstico, e como fato inexorável à maioria dos avanços tecnológicos ao longo da história da humanidade, o computador e, por extensão, outros suportes eletrônicos digitais -já são reconhecidos como ferramentas educacionais, para suporte à aprendizagem, inclusive para crianças pequenas (National Association for the Education of Young Children (Naeyc, 1996); Clements \& Sarama, 2003; Korat \& Shamir, 2006; Haugland, 1999; 2000). Diversos estudos comprovam que, quando softwares são desenvolvidos de acordo com parâmetros que atendem às necessidades de desenvolvimento da faixa etária à qual se destina e a tecnologia é bem empregada ${ }^{10}$ (Korat \& Shamir, 2006), as crianças usuárias apresentam progressos em várias áreas como uso da linguagem, vocabulário, controle motor fino e habilidades sociais e cognitivas (De Jong, 2006; Bus \& De Jong, 2003; Korat \& Shamir, 2004; 2006; Korat, 2006).

Visto sob o prisma do design, cabe um lugar de destaque para alguns dos aspectos ergonômicos relativos à usabilidade das interfaces digitais desenvolvidas para crianças. Baseados em um conjunto de pesquisas, Haugland \& Wright (1997) definiram critérios sobre algumas das questões que, incluindo as mencionadas anteriormente, determinariam o que seria "bom e apropriado" em peças interativas para crianças, e construíram um sistema de avaliação que vem sendo utilizado por pesquisadores (Crenzel, 2009, De Jong, 2006; De
Jong \& Bus, 2003; Korat \& Shamir, 2004, 2006; Madej, 2003).

Dando continuidade a esses estudos e, após esta contextualização, será apresentado o percurso metodológico que foi seguido para desenvolver a pesquisa vinculada a este relatório em que uma narrativa digital e interativa, desenvolvida respeitando os parâmetros acima definidos, para avaliar a influência de um novo tipo de ferramenta instrucional voltado a crianças surdas no intuito de ajudá-las a ampliar o seu repertório sígnico do mundo e, paralelamente, a forma de expressá-los e entende-los em sua segunda língua, o português.

\section{Método adotado}

Neste estudo, foi adotado um método qualitativo por configurar-se como o mais adequado ao tamanho da amostra de sujeitos disponíveis para participação na pesquisa e por haver diferenças significativas nos estágios de capacitação intelectual de cada um deles, bem como de inclusão ou não em turmas de educação regular e grau de conhecimento prévio de conceitos em geral e de palavras em português em particular.

A pesquisa aqui relatada desenvolveu-se através de um estudo exploratório integrando observação intensiva e entrevistas, para o qual foram moldados um instrumento de estímulo na forma de livro infantil em dois formatos e um glossário verbal escrito como apoio à coleta de dados oral e gestual (LIBRAS). A exploração de uma história apresentada em duas versões, ambas digitais a serem acessadas por meio eletrônico, uma com ilustrações animadas, texto verbal escrito em português e vídeo em LIBRAS e a outra com os mesmos recursos e diagramação, entretanto, com ilustrações estáticas. O perfil qualitativo da pesquisa possibilitou fundamentar em profundidade uma compreensão do fenômeno investigado. A escolha do método se deu no sentido de tentar "abarcar a singularidade dos fenômenos que não podem ser

10 Tradução livre da frase "Evidence has accumulated showing a positive effect of well-designed software on young children's cognitive and social development"

Realização:
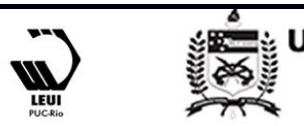




ERGODESIGN USIHC CINAHPA

compreendidos ou explicados pela aplicação de questionários ou de formulários" (Lima, 2008, p. 44).

A participação dos sujeitos, a observação e as entrevistas ocorreram individualmente. $\mathrm{O}$ registro das entrevistas foi feito por gravações de vídeos digitais de curta duração; por fotografias e apontamentos manuais incluindo a transcrição ao português dos relatos em LIBRAS feitos pelos participantes da pesquisa após interagirem com o livro digital. A análise das informações coletadas presencialmente foi posteriormente complementada pelo exame visual dos documentos de registro da observação dos sujeitos participantes ao longo de toda a pesquisa.

\subsection{Narrativa escolhida}

O livro escolhido foi "Guilherme Augusto Araújo Fernandes" de Mem Fox com ilustrações de Julie Vivas (2005), e resultou da boa qualidade da narrativa verbal aliada ao fato de existir uma versão digital para essa história, incluindo vídeos com tradução dos textos verbais do português para LIBRAS. Tanto a coordenadora pedagógica da escola participante da pesquisa como os docentes à frente das turmas com alunos surdos, manifestaram considerar que havia coerência entre o conteúdo narrativo verbal e pictórico em todas as páginas ou telas (Camargo, 2005), e que o relato verbal da história se desenrolava com ritmo adequado e progressão clara (Shulevitz, 1997).

Trata-se da história de um menino que mora vizinho a um asilo de velhos e conversa com todos eles, mas tem carinho especial por uma senhora que, como ele, tem quatro nomes. Todos gostam muito dela, inclusive os pais de Guilherme, mas lamentam que tenha perdido a memória. Guilherme começa, então, a tentar entender o que é MEMÓRIA para tentar recuperá-la para sua amiga do asilo. De cada pessoa a quem pergunta recebe uma resposta diferente: "memória é algo quente", "memória é algo que vale ouro", "memória é algo que faz sorrir"... Então ele começa a coletar objetos que para ele representam calor, que vale ouro, que o faz sorrir... Ele junta tudo num cesto e o leva à senhora sua amiga $\mathrm{e}$ vizinha que fica muito contente ao recebe-las e diz, "que criança adorável que me traz estas coisas $16^{\circ}$ Ergodesign - Congresso Internacional de Ergonomia e Usabilidade de Interfaces Humano Tecnológica: Produto, Informações Ambientes Construídos e Transporte

$16^{\circ}$ USIHC - Congresso Internacional de Ergonomia e Usabilidade de Interfaces Humano Computador

CINAHPA | 2017 - Congresso Internacional de Ambientes Hipermídia para Aprendizagem.

maravilhosas". Guilherme vai entregando e a senhora vai tomando um a um desses objetos e, com cada um deles, por seu significado, vai recuperando lembranças do passado.

Todos os elementos de comunicação visual foram recriados para atender às necessidades especiais desta pesquisa. Quando a elaboração do material foi concluída, ambas versões foram testadas junto em um grupo de foco de cinco jovens surdos com o auxílio de um tradutor de LIBRAS.

\subsection{Instrumentos de estímulo: montagem e construção}

Para a construção dos instrumentos, passamos pelos estágios de elaboração do roteiro de animação (storyboard), montagem das personagens (model sheets), cenários e na construção do livro digital em si. As versões finais do livro digital foram ajustadas após a interação da pesquisadora com um grupo de foco, quando os surdos participantes propuseram modificações estruturais nas telas: para eles as imagens pictóricas - estáticas ou animadas deveriam vir em primeiro lugar, sendo o texto verbal apresentado sob as ilustrações e os vídeos em LIBRAS ao seu lado, e menores, proporcionalmente, em tamanho físico, às utilizadas na fase piloto. De posse das animações, o livro digital foi montado. Todas as páginas foram conectadas e foram criados

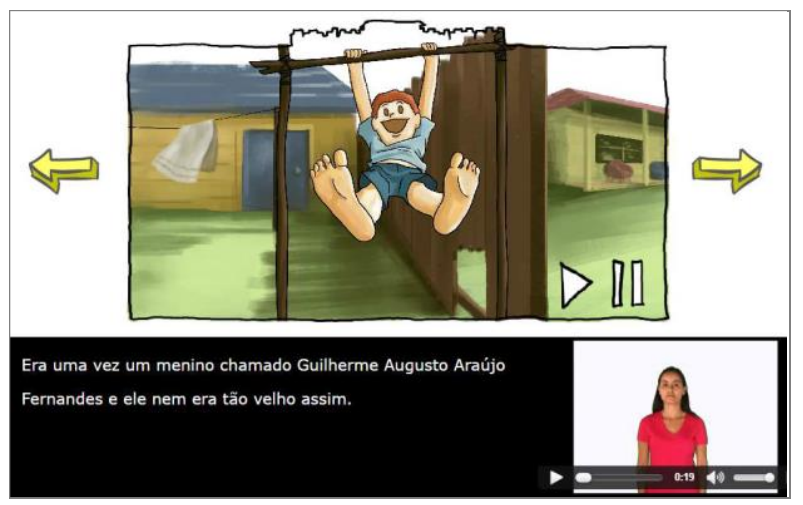

Tela 1 de conteúdo do livro digital animado.

os atalhos (links), para "voltar à cena anterior" e "próxima cena" e acesso a todas a cenas a qualquer momento através de um sumário eletrônico. Salvo nas cenas que mostram Guilherme indo de sua casa






\section{$16^{\circ}$ \\ ERGODESIGN USIHC CINAHPA}

ao asilo de velhos e na que Dona Antônia relembra a sua ida à praia de bonde num dia quente de verão na sua juventude, em todas as outras, as personagens ganharam apenas pequenos movimentos localizados, uma vez que a intenção não era a de transformar o objeto "livro eletrônico" em "desenho animado", mas, apenas, dar algum movimento para estimular o interesse na interação, visando, ainda, que o formato permitisse que as crianças se mantivessem focadas no conteúdo narrativo. $\mathrm{Ou}$ seja, as animações não continham brincadeiras que pudessem desviar a atenção dos leitores para longe do texto verbal: as animações foram planejadas e implementadas para apenas complementarem a ação sugerida nas imagens de cada página transformada em cena. Isto, por entendermos que deva ser esta função da ilustração em uma história infantil, seja estática ou animada. Os elementos de interatividade, incorporados nesta versão, ficaram restritos aos botões de retrocesso, avanço, replay e índice. Seguindo regras do que se considera mais adequado para leitura em monitores, a fonte Verdana foi utilizada para o texto verbal na versão digital, por ter sido especialmente desenvolvida para uso na tela, em tamanho 14, com espaço entrelinhas duplas (Santa Maria, 2002). Todas as telas incluíam opções para voltar à tela anterior, ir à lista de cenas, avançar à cena seguinte e um botão para rever a animação. As crianças receberam instruções de como interagir com a interface antes de iniciarem a leitura. $\mathrm{O}$ número de crianças envolvidas condiz com as orientações recebidas em aulas da disciplina de Análise do Discurso, ministrada por Ana Maria Nicolacci-da-Costa. Segundo ela, um grupo entre 12 e 15 sujeitos constitui uma amostra adequada para pesquisas qualitativas ${ }^{11}$.

As crianças que participaram desta pesquisa interagiram com a narrativa sob o olhar da entrevistadora com o auxílio de um aluno de graduação em design da UFMA, em fase de elaboração de TCC e que também se basearia nessa história para seu trabalho de conclusão de curso. Após a apresentação, às crianças, da interface no computador, quando se propunha que começassem por ver as ilustrações, seguidas da leitura do texto $16^{\circ}$ Ergodesign - Congresso Internacional de Ergonomia e Usabilidade de Interfaces Humano Tecnológica: Produto, Informações Ambientes Construídos e Transporte

$16^{\circ}$ USIHC - Congresso Internacional de Ergonomia e Usabilidade de Interfaces Humano Computador

CINAHPA | 2017 - Congresso Internacional de Ambientes Hipermídia para Aprendizagem.

verbal e/ou acompanhamento da interpretação em LIBRAS, mas deixando claro que era importante que olhassem as três coisas.

As crianças eram deixadas à vontade para ler / interagir no tempo de cada uma, sem que se estabelecesse qualquer tipo de condição. Portanto, foi possível observar o comportamento de cada uma delas, enquanto se entendiam com o relato. Para não constrangê-las ou intimidá-las com a presença de adultos (sugerindo algum tipo censura ou limite de tempo), a observação feita foi de uma certa distância.

Ao longo de dois meses, as crianças participantes leram a história, individualmente, conforme a disponibilidade de tempo e equipamento livre na escola no dia dedicado a cada uma. Foram observadas, gravadas e fotografadas, enquanto interagiam com a narrativa.

As crianças do turno da tarde tiveram uma aula inicial com a docente responsável pela turma para terem um primeiro contato com o glossário da história que veriam posteriormente. Elas não foram incluídas na sala de aula de ensino regular por ainda não dominarem o português minimamente $o$ necessário para isso. Elas estão -

independentemente de suas idades e anos em curso - com uma professora bilíngue (português e LIBRAS), além de contarem com o auxílio de uma intérprete de LIBRAS uma vez por semana. Nesse dia, selecionados junto com o auxílio da professora da turma a partir do conteúdo verbal da narrativa com a qual interagiriam posteriormente nesta pesquisa, uma lista de termos, conceitos e palavras que poderiam - e a maioria provou-se - ser novos para a maioria dessas crianças - foi apresentada a elas tanto em sinais - LIBRAS - como na grafia em português e datilologia, que é uma forma de comunicação mediante sinais feitos com os dedos, usada entre surdos-mudos; também conhecida como quirologia. Nesta forma de comunicação cada sinal com os dedos representa uma letra de alfabeto verbal.

\begin{tabular}{|l|l|}
\hline Piano & Gargalhadas \\
\hline Segredo & Mingau \\
\hline
\end{tabular}

${ }^{11}$ Notas de aula. Disciplina Análise do Discurso, 2005-1 Programa de doutorado - PUC-Rio

Realização:

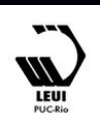




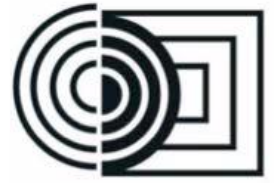

ERGODESIGN USIHC CINAHPA

\begin{tabular}{|l|l|}
\hline Coitado & Compartilhar \\
\hline Lembrar & Vivia \\
\hline Antigo & Medalha \\
\hline Vale ouro & Fresquinho \\
\hline Procurar & Perder \\
\hline Marionete & Guerra \\
\hline Conchas & Cesta \\
\hline
\end{tabular}

Tabela 2

Todas as crianças repetiram os sinais relativos a cada um desses itens, exaustivamente explicados pela professora com gestos e sinais previamente conhecidos por elas, aos que ela acrescentou a datilologia - que eles também imitaram - e o sinal correspondente a cada conceito em LIBRAS. A partir do dia seguinte foram feitas visitas à escola quase diariamente para conseguir algum intervalo de tempo em que uma de cada uma dessas crianças pudesse ser liberada da aula formal para interagir com o livro digital. Antes de a criança ser apresentada ao livro digital ela deveria marcar numa lista impressa que reproduzia os termos previamente ensinados, aqueles que cada uma conhecia e cujo significado lembrava. Após cada interação, sempre acompanhada pela professora ou intérprete de LIBRAS da turma, cada criança recebia um novo glossário idêntico ao inicial para marcar as palavras, termos ou conceitos identificados por elas depois desse novo contato, visual e interativo. As crianças da tarde se comunicaram quase exclusivamente por sinais traduzidos pela intérprete ou professora, raramente recorrendo à datilologia.

As crianças mais velhas e incluídas (turno da manhã), receberam o glossário para marcarem as palavras, conceitos ou termos que já conheciam sem receberem qualquer outra orientação que a de marcarem o que já entendiam. Após a leitura e interação com a história, essas crianças mais velhas, tal como as do turno da tarde, receberam o glossário novamente para acrescentarem as palavras, termos ou conceitos apreendidos pela leitura e interação com a história no computador. Após o término de cada sessão de leitura, aquelas que se dispuseram a recontar a história foram entrevistadas tendo a pesquisadora como orientadora do processo e o auxílio da intérprete de LIBRAS da turma a que cada criança pertencia. As entrevistas foram gravadas e posteriormente transcritas. As $16^{\circ}$ Ergodesign - Congresso Internacional de Ergonomia e Usabilidade de Interfaces Humano Tecnológica: Produto, Informações Ambientes Construídos e Transporte

$16^{\circ}$ USIHC - Congresso Internacional de Ergonomia e Usabilidade de Interfaces Humano Computador

CINAHPA | 2017 - Congresso Internacional de Ambientes Hipermídia para Aprendizagem.

transcrições acrescidas de comentários baseados em anotações a partir da observação da entrevistadora, foram os documentos analisados para a conclusão do presente trabalho. Por tratar-se de entrevistas não-estruturadas, foi definida somente que respondessem a uma única solicitação: "por favor, conte-nos a história que você acaba de ver"

\section{A Pesquisa}

A etapa final deste estudo foi conduzida numa escola municipal da cidade de São Luís - MA, que, em 2016, contava com treze crianças surdas de diversas idades e em diversas etapas de desenvolvimento intelectual. A maioria das crianças participantes do estudo já está parcialmente alfabetizada em português. Isso significa que conseguem identificar as letras do alfabeto, juntar palavras, apreender alguns conteúdos e se expressar por escrito. Algumas, entretanto, ainda estão em fase inicial de alfabetização, principalmente entre as crianças menores que frequentam o turno da tarde $\mathrm{e}$ ainda não estão incluídas em turmas do ensino regular. As menores, também, ainda têm um repertório em LIBRAS mais restrito, uma vez que, embora seja essa a língua natural do surdo brasileiro, nenhuma das crianças desse grupo é filha de pais surdos. Ou seja: elas estão aprendendo LIBRAS na escola e entre elas e não a apreendendo como língua natural.

Todas a crianças envolvidas no estudo obtiveram ganhos de vocabulário, tanto em português como de sinais em LIBRAS. O que é verdadeiramente relevante é que todas elas incorporaram novos conceitos em seu repertório sígnico. Todas somaram, pelo menos, quatro novos conhecimentos à sua bagagem.

\begin{tabular}{|l|c|l|l|l|l|}
\hline Nome & Idade & $\begin{array}{l}\text { Cursado } \\
\text { Em 2016 }\end{array}$ & Versão & \multicolumn{2}{l|}{$\begin{array}{l}\text { Vocabulário em } \\
\text { Palavras /conceitos }\end{array}$} \\
\hline Ray (menina) & 7 & $1^{\circ}$ ano & Anim. & $\mathbf{6}$ & $\mathbf{1 1}$ \\
\hline Ane (menina) & 7 & $2^{\circ}$ ano & Anim. & $\mathbf{0}$ & $\mathbf{1 7}$ \\
\hline Fer (menino) & 7 & $2^{\circ}$ ano & Anim. & $\mathbf{6}$ & $\mathbf{1 0}$ \\
\hline Frank (menino) & 10 & $2^{\circ}$ ano & Anim. & $\mathbf{7}$ & $\mathbf{1 1}$ \\
\hline Ian (menino) & 11 & $4^{\circ}$ ano & Anim. & $\mathbf{1 3}$ & $\mathbf{2 7}$ \\
\hline Del (menino) & 11 & $3^{\circ}$ ano & Estática & $\mathbf{5}$ & $\mathbf{9}$ \\
\hline
\end{tabular}

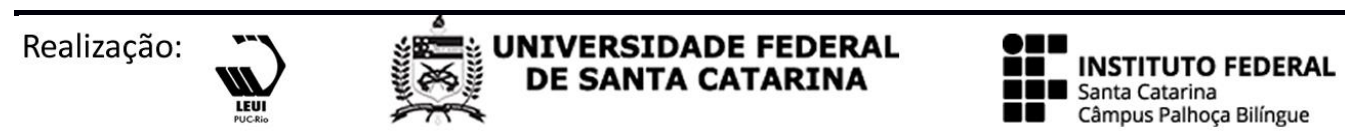


$16^{\circ}$ Ergodesign - Congresso Internacional de Ergonomia e Usabilidade de Interfaces Humano Tecnológica: Produto, Informações Ambientes Construídos e Transporte

$16^{\circ}$ USIHC - Congresso Internacional de Ergonomia e Usabilidade de Interfaces Humano Computador

CINAHPA | 2017 - Congresso Internacional de Ambientes Hipermídia para Aprendizagem.

\begin{tabular}{|l|c|l|l|c|c|}
\hline Ela (menina) & 12 & $4^{\circ}$ ano & Estática & $\mathbf{7}$ & $\mathbf{1 1}$ \\
Joe (menino) & 11 & $6^{\circ}$ ano & Anim. & $\mathbf{4}$ & $\mathbf{1 1}$ \\
\hline Fla (menino) & 11 & $6^{\circ}$ ano & Estática & $\mathbf{3}$ & $\mathbf{7}$ \\
Add (menino) & 12 & $6^{\circ}$ ano & Estática & $\mathbf{4}$ & $\mathbf{1 1}$ \\
\hline Hel (menina) & 12 & $6^{\circ}$ ano & Anim. & $\mathbf{3}$ & $\mathbf{1 0}$ \\
\hline Edu (menino) & 14 & $6^{\circ}$ ano & Anim. & $\mathbf{4}$ & $\mathbf{1 1}$ \\
\hline Ary (menino) & 16 & $9^{\circ}$ ano & Estática & $\mathbf{8}$ & $\mathbf{1 2}$ \\
\hline
\end{tabular}

professora e à intérprete, acomodou-se na cadeira, ergueu as costas e interagiu demoradamente com cada tela que surgia perante ela.

Eventualmente, Ray interrompia a interação para perguntar à intérprete ou à professora, $\mathrm{o}$ significado de algum sinal em LIBRAS dos vídeos, ou uma palavra escrita. As explicações

Tabela 3 - Resultados obtidos

Os dados numéricos acima não constituem uma base para cálculo estatístico, sendo este um estudo essencialmente qualitativo. Os números foram apresentados para servirem como ponto de partida à análise qualitativa a seguir.

\subsection{Alguns resultados individuais}

Ray, ( 7 anos, menina, turno da tarde)

Ray foi a primeira a interagir com a história digital. Pela idade, ela ainda está aprendendo a ler e escrever, bem como LIBRAS e datilologia. Como descrito anteriormente, a primeira etapa tinha sido a apresentação, em aula dada pela professora, de um glossário com termos, expressões, conceitos e palavras que poderiam ser novos para as crianças menores envolvidas no estudo. A mesma lista foi entregue a Ray que teve de marcar os itens por ela já conhecidos, que foram:

$$
\begin{aligned}
& \text { - } \text { Bengala } \\
& \text { - } \text { Piano } \\
& \text { - Marionete }
\end{aligned}
$$

$$
\begin{array}{ll}
\text { - } & \text { Botas } \\
\text { - } & \text { Mingau } \\
\text { - } & \text { Guerra }
\end{array}
$$

Diante do computador, sentada entre a intérprete e sua professora, que deram as orientações de como interagir com a narrativa digital, começou a lidar com a versão com ilustrações estáticas. Ela manuseava corretamente o mouse do computador para passar de uma página a outra e no começo parecia contente e estimulada. Após alguns minutos, quando ainda faltava-lhe interagir com mais da metade da história, ela dava sinais de cansaço e desinteresse. Nesse momento, optamos por alternar as versões do conto, ou seja: ela passou a ver a versão com ilustrações animadas. O rosto de Ra se iluminou. Ela sorriu, olhou para cada lado, mostrando a sua satisfação com o novo objeto à eram dadas com sinais e datilologia. O ponto mais significativo deste encontro aconteceu quando a animação que incluía uma marionete surgira na tela. A professora tinha ensinado o que isso significava no dia anterior, mostrando imagens, gesticulando, encenando, em LIBRAS e datilologia. Entretanto, Ray identificou que o sinal em LIBRAS que a professora tinha mostrado no dia anterior não correspondia integralmente àquele apresentado pela intérprete de LIBRAS do livro digital. Nesse momento, Ray se levantou, aproximou-se da professora, tomou-lhe a mão, e com visível satisfação corrigiu a forma como MARIONETE deveria ser sinalizada. A professora sorriu, a parabenizou em LIBRAS e português, e a abraçou carinhosamente. Foi um momento muito significativo para todos os presentes. Até o final da interação Ray demonstrou verdadeiro prazer em lidar com a história. A seguir, foi-lhe apresentado o glossário novamente recebendo instruções para que marcasse todos os itens por ela reconhecidos nesse momento. À listagem original acrescentou:
- Asilo de velhos

- Arrepiantes

- Gargalhadas
- Procurar

- Amarrar
Ane (menina, 7 anos, turno da tarde)

Ane recebeu o glossário para marcar os termos por ela conhecidos, mas antes da interação com o livro digital nada lembrava. Em vista da experiência vivida com Ray, Ane interagiu diretamente com a versão que incluía animações. A expressão de alegria ao ver os movimentos da tela ficou muito evidente e o resultado em termos de aquisição de novos conhecimentos, superou nossas expectativas. Embora ela não tenha conseguido expressar novo vocabulário em português, ela tinha aprendido um número significativo de novos conceitos que soube expressar em LIBRAS à interprete que, por sua vez, a ajudou a sinalizar na planilha: 
- Bengala

- Gigante

- Piano

- Coitado

- Conchas

- Cesta

- Ninho

- Botas
- Galinheiro
- Amarrar

- Gargalhadas

- Mingau

- Vivia

- Medalha

- Fresquinho

- Perder

- Guerra
Ian, (10 anos, menino, turno da tarde)

Pouco alfabetizado, ele sabe se expressar com propriedade em LIBRAS. A primeira planilha por ele marcada indicava que já conhecia os conceitos:

$\begin{array}{ll}\text { - Antigo } & \bullet \text { Botas } \\ \text { - Vale ouro } & \bullet \text { Amarrar } \\ \text { - Procurar } & \bullet \text { Gargalhadas } \\ \text { - Conchas } & \text { - Mingau } \\ \text { - Cesta } & \bullet \text { Medalha } \\ \text { - Adorável } & \text { - Perder } \\ \text { - Ninho } & \end{array}$

Após a interação com a versão animada do livro ele acrescentou em LIBRAS:

$\begin{array}{lll}\text { - Memória } & \text { - Compartilhar } \\ \text { - Bemar } & \text { - Guerra } \\ \text { - História } & \text { - Arrepiantes } \\ \text { - Vivia } & \text { - Gigante } \\ \text { - Galinheiro } & \text { - } \text { Siano } \\ \text { - Fresquinho } & & \end{array}$

As crianças participantes do estudo demonstraram grande satisfação em poder acompanhar a história pelo computador, nas duas versões. Todas demonstraram desenvoltura para lidar com a tecnologia envolvida e pouco foi necessário explicar a respeito da interface, ou seja, quais eram os links para pular para qualquer página da narrativa a qualquer momento, como avançar, retroceder e controlar as animações ilustradas e os vídeos com interpretações em LIBRAS. Todos os integrantes da amostra adquiriram novos conhecimentos ao longo da interação com a narrativa: os mais velhos principalmente em português, que era a proposta inicial da pesquisa aqui relatada, e as menores ampliaram seu repertório de conhecimentos principalmente em $16^{\circ}$ Ergodesign - Congresso Internacional de Ergonomia e Usabilidade de Interfaces Humano Tecnológica: Produto, Informações Ambientes Construídos e Transporte

$16^{\circ}$ USIHC - Congresso Internacional de Ergonomia e Usabilidade de Interfaces Humano Computador

CINAHPA | 2017 - Congresso Internacional de Ambientes Hipermídia para Aprendizagem.

sinais. Ou seja: eles adquiriram novos conceitos para a bagagem geral de conhecimentos que, naturalmente, para o surdo, se dá inicialmente em LIBRAS.

\section{Considerações Finais}

O trabalho aqui descrito teve como ponto de partida a premissa de que crianças surdas podem se beneficiar de narrativas ilustradas e animadas por serem estes recursos visuais que funcionam como reforços cognitivos para qualquer pessoa e, em especial, para os surdos.

As questões subjacentes que justificaram esta pesquisa podem ser traduzidas com perguntas como: poderão narrativas com ilustrações animadas apresentadas em suportes digitais interativos com reforço visual de tradução a LIBRAS influenciar no processo de estímulo ao prazer de ler por crianças surdas?

Do estudo aqui apresentado surgiram questões diretamente ligadas ao que se pesquisava e descobertas inesperadas, que, acreditamos em muito poderão contribuir na configuração de histórias infantis e material pedagógico-educativo para crianças surdas.

Com relação ao que se pesquisou, ou seja, que tipo de impacto ilustrações animadas poderiam ter como subsídios à aquisição de novas palavras do vocabulário em português por crianças surdas, na amostra estudada, registramos fortes indícios que trata-se de um poderoso recurso para facilitar essa tarefa, uma vez que os relatos da "recontação" da história por crianças integrantes da amostra, deixaram claras pistas de que a informação visual prevalece sobre a verbal quando apresentadas simultaneamente (Crenzel, 2009) e reforçada pela interpretação em LIBRAS.

As descobertas que parecem mais importantes, entretanto, surgiram como resultados paralelos ao fenômeno que se pretendeu estudar. Em primeiro lugar, é que, junto a crianças pequenas, as imagens em movimento e a possibilidade de interação com as interfaces têm um efeito quase mágico para lhes captar a atenção e envolve-las na narrativa. A 


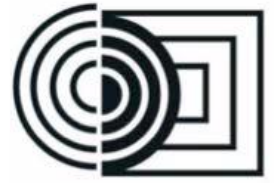
CINAHPA

segunda constatação, atrelada à primeira, é que a fruição da narrativa é fortemente influenciada pela presença de imagens em movimento,

independentemente da idade da criança. Esse é um resultado que só pôde ser aferido por tratar-se de um estudo exploratório de natureza qualitativa baseado em observação direta. Por uma questão ética não podemos mostrar os rostos de felicidade das crianças ao interagirem com a narrativa animada observados ao longo do estudo, mas deixamos aqui registrado como nosso depoimento.

A preponderância da informação pictórica sobre a informação linguística (Crenzel, 2009) ficou clara mais uma vez e, portanto, entende-se que pode haver um amplo leque de aplicações possíveis para o incentivo à leitura, a serem implementadas por todos os profissionais envolvidos no esforço de alfabetizar crianças surdas para que possam dominar o português com eficiência e amplo entendimento, que deverão considerar o poder da imagem pictórica ao desenvolverem novos enredos. Entendemos que os dados - que aqui constam como contribuição desta pesquisa - se bem explorados, podem vir a ser importantes coadjuvantes na elaboração de materiais didáticos que colaborem para promover transformações importantes no processo de aquisição de conceitos - verbais ou visuais - por crianças surdas.

Não nos referimos somente a transformações em conteúdos literários, ou mesmo ao aprendizado do português e da leitura. $\mathrm{O}$ universo de possibilidades abrange todo e qualquer conteúdo que pudesse ser transformado em imagens animadas, já sejam conceitos matemáticos ou de ciências, entre um amplo leque de disciplinas. Acreditamos ser possível vislumbrar um futuro com materiais interativos enriquecidos com ilustrações animadas, tanto junto a crianças em fase de alfabetização, como para as mais velhas que lidam com conceitos mais complexos.

Embora o trabalho aqui descrito tenha contado com uma varredura significativa da literatura já produzida no campo em estudo, não podemos afirmar que tenhamos conseguido abarcar completamente o universo de conhecimento a ele relacionado. Longe de esgotarmos o assunto, $16^{\circ}$ Ergodesign - Congresso Internacional de Ergonomia e Usabilidade de Interfaces Humano Tecnológica: Produto, Informações Ambientes Construídos e Transporte

$16^{\circ}$ USIHC - Congresso Internacional de Ergonomia e Usabilidade de Interfaces Humano Computador

CINAHPA | 2017 - Congresso Internacional de Ambientes Hipermídia para Aprendizagem.

esperamos, somente, ter contribuído na construção do conhecimento para a melhoria dos processos de aquisição da linguagem verbal por crianças surdas que, acima de tudo, poderão vir a lidar com narrativas literárias e materiais didáticos que lhes desenhem sorrisos como os que tivemos a honra e o prazer de testemunhar ao longo desta pesquisa.

\section{Bibliografia}

ABRAHAMS, M.H. A glossary of literary terms. Fort Worth: Harcourt Brace College, 2000.

ALVES, E.de O. O Ensino de Língua Portuguesa para Surdos e a Narrativa em Libras. Disponível em < https://www.youtube.com/ watch?v=Q2oG7sRxcvI > Acesso em 15/12/2014

BROOKSHIRE, J.; SCHARFF, L. F. V.; MOSES, L. E. The Influence of Illustrations on Children's Book Preferences and Comprehension. Reading Psychology. v.23, Is. 4, 2002, p. 323.

CAMARGO, L. A relação entre imagem e texto na ilustração de poesia infantil. 1995. Disponível em: $<$ http://www.unicamp.br/Iel/memoria/ensaios/p oesiainfantilport.htm>. Acesso em: 5 abril. 2007.

\section{CRENZEL. S. R.. A ilustração infantil como} recurso narrativo - Influência das imagens na leitura de histórias por crianças. Tese de doutorado. Pontifícia Universidade Católica do Rio de Janeiro. Departamento de Artes e Design.2009

\section{FERREIRO, E. Passado e Presente dos Verbos \\ Ler e Escrever, São Paulo, Cortez, 2002.}

FOX, M. VIVAS, J. Guilherme Augusto Araújo

Fernandes, DVD com vídeos em Libras. São

Paulo. Brinquebook, 2002.

HAUGLAND, S.; WRIGHT, J. Young children and technology, a world of discovery. New York: Allyn, 1997.

INTERNATIONAL CHILDREN'S DIGITAL LIBRARY, ICDL. Universidade de Maryland. Disponível em: <http://www.childrenslibrary.org/. Acesso em: 15 Jun. 2007.

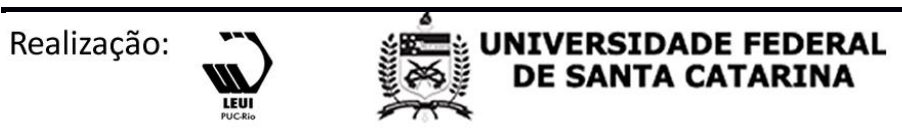




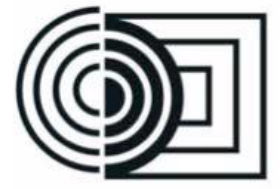

\section{$16^{\circ}$}

ERGODESIGN USIHC CINAHPA

JONG, M. T. Where Did Mister Owl Take Us? are multimedia stories a barrier or walking frame for preschoolers on their way to literacy? KNAW Academy Colloquium. How media can contribute to early literacy. Annals. Amsterdam: Jun.2006.

JONG, M. T.; BUS, A. G. The efficacy of electronic books in fostering kindergarten children`s emergent story understanding. Reading Research Quarterly, n.38. 2004, p. $378-393$.

KORAT O.; SHAMIR, A. Do Hebrew Electronic Books Differ from Dutch Electronic Books? A Replication of A Dutch Content Analysis. Journal of Computer Assisted Learning.2004, n.20,p.257-268.

KORAT, O. Effects of Multimedia Storybooks on Children's Emergent Literacy In: Low-Versus Middle Income Groups In Israel. KNAW Academy Colloquium. How media can contribute to early literacy...Annals. Amsterdam, Jun.2006.

SHULEVITZ, U. Writing with pictures: how to write and illustrate children's books. New York: Watson-Guptill, 1985. $16^{\circ}$ Ergodesign - Congresso Internacional de Ergonomia e Usabilidade de Interfaces Humano Tecnológica: Produto, Informações Ambientes Construídos e Transporte

$16^{\circ}$ USIHC - Congresso Internacional de Ergonomia e Usabilidade de Interfaces Humano Computador

CINAHPA | 2017 - Congresso Internacional de Ambientes Hipermídia para Aprendizagem. 